Escuela de Ciencias Sociales y Humanidades, UNED, C.R.

URL: http://investiga.uned.ac.cr/revistas/index.php/espiga/index

ISSN: 1409-4002 • e-ISSN: 2215-454X

\title{
Jóvenes padres costarricenses: cambios y continuidades de la masculinidad tradicional
}

\section{Carolina Fonseca-Vindas*}

iD https://orcid.org/0000-0001-9554-3224

\author{
Recibido: 03 de diciembre, 2018 - Aceptado: 19 de febrero, 2019
}

\begin{abstract}
RESUMEN
Este artículo surge para evidenciar la estrecha relación entre la construcción de las masculinidades y las formas de vivir y ejercer la paternidad. Vínculo que se investigó con profundidad en la tesis denominada «Ejercicio y concepción de la paternidad en dos grupos de jóvenes padres costarricenses: Cambios y permanencias de los modelos de masculinidad tradicional», cuyos resultados son muy sugerentes para comprender el porqué los hombres asumen su paternidad de determinada manera, cómo influye eso en su vida diaria y emocionalidad y, sin duda, el papel de la sociedad patriarcal en sus aprendizajes, creencias y comportamientos. Por lo tanto, parte de la importancia de esta investigación radica en aportar líneas e insumos a estudios e intervenciones venideras, sobre el trabajo con padres jóvenes y la relación con la masculinidad dominante. Aunado a la urgencia de repensar la «paternidad responsable» que se concibe a nivel institucional-gubernamental, desde un nuevo paradigma enfocado en el involucramiento afectivo y comprometido en las labores de cuido y crianza. Esto lleva a cuestionarse el enfoque e impacto de la Ley de Paternidad Responsable, la Ley de Pensiones Alimenticias y el Código de Familia, mediante un análisis integral de su contenido, con conocimiento de cuál ha sido el manejo jurídico de dichas leyes en la realidad de muchos padres. Esta investigación pone sobre la balanza
\end{abstract}

\section{Formato de citación según APA}

Fonseca Vindas, C. (2019). Jóvenes padres costarricenses: cambios y continuidades de la masculinidad tradicional. Revista Espiga, 18 (37), 14-39.

\section{Formato de citación según Chicago-Deusto}

Fonseca Vindas, Carolina (2019). «Jóvenes padres costarricenses: cambios y continuidades de la masculinidad tradicional». Revista Espiga 18, n. ${ }^{\circ} 37$ (enero-junio, 2019): 14-39.

* Bachillerato y licenciatura en Sociología de la Universidad Nacional (UNA). Diplomado en Estudios de Masculinidades de la Organización Multidisciplinaria Latinoamericana en Estudios de Masculinidades (OMLEM), Argentina. Académica de la Universidad Técnica Nacional (UTN), Costa Rica. Correo: cfonseca@utn.ac.cr 
múltiples aspectos que constituyen la paternidad de los jóvenes entrevistados y, con esto, una rigurosa comprensión de sus masculinidades y la forma en que han sido consolidadas.

Palabras clave: Hombres, crianza, participación de los padres, contexto cultural, investigación social.

\section{Elementos introductorios y principales referentes teóricos}

Esta investigación parte con una revisión documental, a nivel nacional e internacional, sobre los estudios de los hombres y, posteriormente, se profundiza en la relación de la construcción del «ser hombre» y «ser padre», con la intención de mirar la influencia de la socialización patriarcal en las prácticas de la paternidad. En esta primera fase de investigación bibliográfica, y con las observaciones de la vida cotidiana, se determina la relevancia de incorporar los estudios sobre las condiciones de los hombres, como parte fundamental del enfoque de género. Dicha preocupación surge al evidenciar los vacíos existentes en diversos espacios académicos, de investigación y acción social del entorno costarricense, los cuales requieren una inclusión más asertiva y empática del abordaje de las masculinidades en la lucha por la equidad de género.

Esto permite preguntarse: ¿Prevalece un trabajo aislado y vertical de algunos grupos con perspectiva de género en Costa Rica? ¿Por qué no se ha consolidado un trabajo coordinado y en conjunto entre organizaciones que trabajan la violencia contra la mujer y quienes abordan la problemática con varones? ¿Han caído estas posturas en un reduccionismo analítico? ${ }^{1}$

Sin duda, es necesario un proceso de autocrítica y revisión de los paradigmas que muchas posturas predican, pues parece que, buena parte de las explicaciones para entender la violencia contra las mujeres, radican señalizar el rol dominante y agresivo de ser hombre y se dejan de lado los siguientes cuestionamientos: ¿Por qué los hombres son enseñados a ser violentos? ¿Cómo influye la mala gestión de las emociones masculinas en dichos actos de violenta? ¿Cuál es la importancia de los estudios sobre masculinidades en las acciones de prevención y compresión de la desigualdad de género? Estas preguntas son parte fundamental de la propuesta epistemológica de este trabajo y a lo largo del texto se argumentan con los resultados de la investigación.

Estos primeros cuestionamientos surgen en la fase inicial de la investigación y posteriormente se clarifican los objetivos del estudio; el primero se centra en analizar cómo las practicas paternas de un grupo de jóvenes padres evidencian una continuidad de los

1. Se entiende por reduccionismo analítico, en este caso, a aquellas explicaciones sobre la desigualdad de género que únicamente se centran en victimizar a las mujeres y señalar a los victimarios como responsables de dicha opresión. Sin analizar de manera objetiva el trasfondo de dichos comportamientos opresivos, y reproduciendo una retórica que lejos de aportar a la lucha, redunda y actúa en una sola línea, provocando estancamiento y poca empatía en otros grupos sociales. 
modelos de masculinidad tradicional y, al mismo tiempo, cómo se manifiestan rupturas o cambios de esas imposiciones sociales de las que han sido parte a lo largo de sus vidas.

La sistematización de los principales estudios nacionales e internacionales sobre la temática fue muy provechosa y dio luces sobre los aspectos ampliamente estudiados y aquellos que requieren mayor profundización. Más adelante se hace un breve recuento sobre dichos aportes, volviendo la mirada a la perspectiva latinoamericana.

Asimismo, con el estudio de los hombres y sus vivencias como padres, se hizo una articulación de diversas corrientes de pensamiento sociológico, lo que permitió dimensionar el fenómeno social investigado. La sociología del conocimiento de Karl Mannheim, la sociología comprensiva de Max Weber, que explica el trasfondo de la acción social, la fenomenología de Alfred Schutz, el interaccionismo simbólico de G. H. Mead y la etnometodología de Erving Goffman, son solo algunos referentes teóricos que la sociología aporta al estudio de las relaciones interpersonales, a la construcción de las subjetividades para explicar la complejidad de las relaciones de género.

La estructura teórica de la investigación se compuso de una serie de temáticas centrales para explicar la construcción de las masculinidades en el ejercicio paterno. Se categorizaron los siguientes aspectos: el ideal masculino, rituales de iniciación, interiorización de la dominación, la presión por ocupar el rol de varón, el mandato de la proveeduría masculina en la práctica paterna, la paradoja de la demostración de afecto en el ejercicio de la paternidad y la feminización de la reproducción y el cuido.

A grandes rasgos, cabe mencionar los componentes centrales alrededor del objeto de estudio.

\section{Poder: Constitución de la masculinidad hegemónica}

El papel de la sociología en la construcción de conocimientos sobre la realidad social, pretende entender el porqué del comportamiento humano, ubicándose en los condicionamientos contextuales, coyunturales y estructurales. En este sentido, la disciplina sociológica entiende la realidad del hombre desde un prisma multidimensional, primero desde un plano estructural (patriarcado) y, segundo, desde las particularidades de su individualidad, elementos vivenciales como las relaciones familiares, las condiciones socioeconómicas, etnia, orientación sexual y ubicación geográfica, entre otros.

Estas características dotan de heterogeneidad a la masculinidad, no obstante, hay un elemento en común: la adquisición y reproducción de poder. Michel Foucault desarrolla el concepto de microfísica del poder (mismo nombre de su obra) y realiza una comparación de los procesos subatómicos (micro) y las relaciones interpersonales cargadas de significaciones sociales, al «percibir la singularidad de los sucesos, fuera de toda finalidad monótona; encontrarlos allí donde menos se espera y en aquello que pasa desapercibido por no tener nada de historia -los sentimientos, el amor, la conciencia, los instintos» ${ }^{2}$.

2. Michel Foucault, Microfisica del Poder (Madrid: Las Ediciones de La Piqueta, 1979), 7. 
Esta singularidad de la que habla Foucault es la que se encuentra cargada de prácticas de poder y, en este sentido, cobra especial importancia la lingüística y el plano discursivo, pues en el lenguaje se pueden palmar representaciones de la realidad, atinente al problema aquí expuesto. A la vez menciona que «las relaciones de poder penetran en los cuerpos $»^{3}$. Esto no solo atraviesa los requerimientos de la sociedad heteronormativa, sino también la internalización de conductas de acuerdo con roles de género.

En esta línea es pertinente explicar qué se entiende por el término masculinidad tradicionalldominante o hegemónica y cuál es la relación de estas tipificaciones con el ejercicio de la paternidad. Los insumos conceptuales sobre el tema exponen esta compleja relación y la repercusión en todas las esferas de la vida social. Autoras como Elisabeth Badinter ${ }^{4}$, Raewyn Connell ${ }^{5}$, Michael Kaufman ${ }^{6}$ y Michael Kimmel ${ }^{7}$, coinciden en senalar las características principales de la construcción de las masculinidades; la primera tiene que ver con la legitimación del poder masculino en todos los espacios de la sociedad: lugares de trabajo (espacio público) y en el hogar (espacio privado), con esto se deben entender las relaciones de género basadas en dominación, en donde lo masculino impera sobre lo femenino y ha tenido su consolidación histórica, por ejemplo, con los procesos de industrialización y con esto la división sexual del trabajo, que hizo una marcada separación de roles.

En este sentido, autoras con Nancy Chodorow ${ }^{8}$, Raewyn Connell ${ }^{9}$ y Judith Butler ${ }^{10}$, en diferentes periodos, coinciden en la estrecha relación entre poder o adquisición de este y el cambio en las mentalidades, en un proceso de interiorización y, por lo tanto, normalización de la dominación, lo que conlleva también a la aceptación de la inferioridad. Estos elementos son fundamentales para comprender el «género» y las posturas ontológicas y explicativas de sus condiciones.

Butler arguye que la idea de que el sujeto está apasionadamente apegado a su propia subordinación, ha sido invocada cínicamente por quienes intentan desacreditar las reivindicaciones de los subordinados. El razonamiento es el siguiente:

«Si se puede demostrar que el sujeto persigue o sustenta su estatuto subordinado, entonces la responsabilidad última de su subordinación quizás resida en él mismo. Por encima y en contra de esta visión, yo argumentaría que el apego al sometimiento es producto de los manejos del poder, y que el funcionamiento del poder se transparenta parcialmente en este efecto psíquico, el cual constituye una de sus producciones más insidiosas» ${ }^{11}$.

3. Foucault, Microfisica ..., 153 .

4. Elisabeth Badinter, XY La identidad masculina (Madrid: Alianza Editorial, 1993).

5. Raewyn Connell, Masculinities (Cambridge: Polity Press, 1995).

6. Michael Kaufman, «Los hombres, el feminismo y las experiencias contradictorias del poder entre los hombres» (1994), acceso: 06 de mayo, 2019, http://www.michaelkaufman.com/wp-content/uploads/2008/12/ los-hombres-el-feminismo-y-las-experiences-contradictorias-del-poder-entre-los-hombres.pdf

7. Michael Kimmel, «Homofobia, temor, vergüenza y silencio en la identidad masculina» (1997), acceso: 06 de mayo, 2019, http://www.lazoblanco.org/wp-content/uploads/2013/08manual/bibliog/material_masculinidades_0434.pdf

8. Nancy Chodorow, La reproducción de la maternidad: Psicoanálisis y Sociología de Género (Londres: Universidad de California Press, 1979).

9. Connell, Masculinities, 1995.

10. Judith Butler, Mecanismo psíquicos de poder: teorías de la sujeción (Valencia: Ediciones Cátedra, 2001).

11. Butler, Mecanismo..., 17. 
Cabe afirmar que «la masculinidad es más importante para los hombres que la feminidad para las mujeres» ${ }^{12}$. Ante dicha demanda, los hombres sienten el deber de cumplir con una serie de exigencias y así no correr el riesgo de ser feminizados, lo que se traduce muchas veces en ser señalado como homosexual. Gilmore plantea que en las diferentes culturas se le pide a los varones actuar como «hombres de verdad» bajo la lógica de enaltecer su virilidad, lo que se convierte en una «virilidad bajo presión» ${ }^{13}$.

La esencia del ideal masculino se basa en reproducir y reafirmar cotidianamente la superioridad que la sociedad patriarcal les ha otorgado. Dicha obtención representa un arma de doble filo y un peso para hacer valer dichas atribuciones; con esto, los hombres se preocupan por cumplir con ciertos mandatos, como tener éxito económico, autocontrol de las emociones, virilidad sexual, poseer fuerza física y tener habilidades para los deportes; solo por mencionar algunos.

Con esto, otro elemento teórico central para entender cómo se compone la identidad masculina, es la construcción en oposición a lo considerado femenino, es decir, se les enseña a los varones desde los primeros años de vida, a comportarse e identificarse con rasgos que sean contrarios a aquellos asignados como femeninos. Todo lo relativo a lo pasivo, frágil y dependiente, son características asociadas a las mujeres, por lo tanto la conducta masculina debe ser una reivindicación cotidiana para no acercarse a lo feminizado. En relación con este tema, la reivindicación va directamente de la mano con la constante demostración de hombría; en esta línea Jociles afirma que abundan las situaciones y los contextos (como los deportes, en especial los de riesgo, las peleas entre pandillas, las borracheras, los espectáculos de toros, ciertos juegos o determinadas prácticas temerarias, para poner unos casos) en donde los jóvenes y adolescentes tratan de «demostrar» públicamente su virilidad ${ }^{14}$.

Menjívar ${ }^{15}$ señala que, en las demandas de la masculinidad hegemónica, a los hombres se les limita la expresión de sentimientos, deben permanecer fríos y fuertes y no optar por comportamientos feminizados (pasividad, ternura, compasión). Estas características asociadas a lo femenino-materno, son la antítesis al comportamiento esperado por los hombres; por ese motivo, no se espera que lo masculino-paterno cumpla con esos requerimientos. Por el contrario, se les demanda una reafirmación de su hombría manifestada en diferentes acciones. Esta demostración de hombría va de la mano con el concepto de rituales de iniciación, acuñado por David Gilmore, los cuales son prácticas que reproducen los hombres desde temprana edad, para validar su masculinidad. Por ejemplo: jugar futbol, involucrarse en peleas, no expresión de debilidad, iniciación sexual, etc.

12. Helen H. en Elisabeth Badinter, XY La identidad masculina (Madrid: Alianza Editorial, 1993), 51.

13. David Gilmore en María José Jociles, «El estudio sobre masculinidades: Panorámica general», Facultad de Ciencias Políticas y Sociología, Universidad Complutense de Madrid, acceso: 06 de mayo, 2019, http:// www.ugr.es/ pwlac/G17_27MariaIsabel_Jociles_Rubio.html

14. Jociles, «El estudio...», 2001.

15. Menjívar, Mauricio, «Hombres inventados. Estudios sobre masculinidad en Costa Rica y la necesidad de nuevos supuestos para el cambio social» (2007), Diálogos, Revista Electrónica de Historia, Vol. 8, n. ${ }^{\circ}$ 1, Escuela de Historia, Universidad de Costa Rica, acceso: 06 de mayo, 2019, https://revistas.ucr.ac.cr/index. $\mathrm{php/dialogos/article/view/6165}$ 
Un ejemplo ampliamente citado en los estudios antropológicos es el caso de una tribu de Nueva Guinea:

«entre los sambia, los ritos de iniciación a la virilidad, que los niños atraviesan a partir de los 7-8 años, empiezan con la separación de los muchachos de la proximidad de la madre, llevándolos a un lugar del monte exclusivamente masculino, donde permanecerán unos 10 años. (...) serán sometidos a numerosas pruebas y vejaciones, algunas de las cuales incluyen palizas o sangrías. Una de las más dolorosas es la 'hemorragia nasal', que se les produce introduciendo en la nariz hierbas recias y ásperas, y que han de saber soportar estoicamente. La interpretación que los propios sambia dan de 'esta hemorragia nasal' es que consiste en quitar del cuerpo de los muchachos 'la sangre y la leche', amén de otras influencias femeninas contaminantes, por cuanto estas influencias femeninas inhiben la masculinización y, por tanto, el desempeño del papel de varón» ${ }^{16}$.

Actualmente, dichas significaciones sobre demostración de masculinidad cobran sentido en las realidades de muchos hombres desde la infancia, las relaciones familiares y grupos de pares. Un elemento central dentro de dichos vínculos es la relación con el padre desde sus primeros años de vida, en donde la ausencia, el abandono o la poca participación en la vida de estos jóvenes, representa una determinante en la adopción de ciertos comportamientos y formas de enfrentar sus experiencias de vida.

El aporte teórico de los agentes socializadores en la construcción de masculinidades dominantes o tradicionales, tiene un papel fundamental en la explicación de fenómenos como la violencia intrafamiliar, el abandono paterno, los elevados índices de muertes masculinas (por ejemplo, accidentes de tránsito y suicidios), dando pistas muy certeras de cómo la sociedad patriarcal ha constituido en los hombres un mal manejo de las emociones, que repercuten en sus psiquis y en sus relaciones con los demás.

Desde su visión psicoanalítica, Chodorow profundiza las implicaciones de las relaciones padre-hijo/a, madre-hijo/a en la internalización de rasgos conductuales. «Las madres son y han sido cuidadoras, socializadoras el objeto substitutivo primario; los padres son objetos secundarios para varones y mujeres. Mi interpretación del complejo de Edipo, desde una perspectiva centrada en las relaciones objetuales, muestra que estos rasgos de la estructura familiar traen aparejados variadas formas de diferenciación para el ego y sus relaciones objetuales relacionadas y conducen al desarrollo de diferentes capacidades de relacionamiento para muchachos y muchachas $\rangle^{17}$.

Si bien no todos viven los primeros años de su vida en una familia nuclear, la gran mayoría sí, y esas relaciones iniciales marcan pautas en la interiorización de patrones de conductas y hay un proceso paulatino de trasmisión de saberes. En el caso de los varones, la primera figura de identificación es la del padre, pues es el modelo masculino al cual imitar. Las cualidades de proveedor económico, control, independencia, fuerza, no demostración de fragilidad y afecto, son concebidos como propios y, por ende, reproducidos en sus diferentes etapas de la vida.

16. Jociles, «El estudio...», 2001.

17. Chodorow, La reproducción..., 92. 
Estas exigencias resultan ser un arma de doble filo, pues «a pesar de que la masculinidad es una posición de prestigio, se trata de una identidad que se vive a menudo desde la carencia y la imposibilidad de cumplir con sus imperativos», (...) «especialmente en lo que concierne a temas relacionados con el espacio exterior, la casa misma (especialmente, la cocina) se define como femenina, y cuando un varón está entre sus cuatro paredes, corre el riesgo de ser feminizado por su contacto» ${ }^{18}$. Este tipo de construcciones basadas en la feminidad y masculinidad representa una presión por cumplir con las expectativas de la sociedad y así, evitar situaciones de rechazo y ser juzgados por el entorno en que se desenvuelven. Esto quiere decir que la demanda persistente en demostrar hombría es un requisito nocivo al desarrollo integral de los varones, particularmente en el desempeño de la paternidad.

Para continuar esclareciendo los elementos que constituyen las masculinidades ${ }^{19}$, los aportes de Pierre Bourdieu, en su texto La dominación masculina, permiten entender de una forma más global el impacto de una serie de procesos socioculturales en la interiorización paulatina e inconsciente de rasgos que definen lo masculino y, por ende, se traduce en la adquisición de poder y la ejecución de esa superioridad. Con esto, las mujeres también han aprehendido cualidades y actitudes que hacen normalizar una condición de inferioridad, siendo cómplices de cualquier relación de subordinación hacia los hombres.

Esta dominación repercute en las manifestaciones de la corporalidad femenina y masculina:

La moral femenina se impone sobre todo a través de una disciplina constante que concierne a todas las partes del cuerpo y es recordada y ejercida continuamente mediante la presión sobre las ropas o la cabellera. Los principios opuestos de la identidad masculina y de la identidad femenina se codifican de ese modo bajo la forma de maneras permanentes de mantener el cuerpo y de comportarse, que son como la realización o, mejor dicho, la naturalización de una ética. Del mismo modo que la moral del honor masculino puede resumirse en una palabra, cien veces repetida por los informadores, qabel, enfrentarse, mirar a la cara, y en la postura correcta (la de nuestro «firmes» militar) ${ }^{20}$.

Estos rasgos masculinizados, de rigidez, firmeza y frialdad han atravesado la esfera de lo privado: las relaciones familiares; y han abarcado la participación paterna en el cuido y crianza de los hijos/as.

El orden social funciona como una inmensa máquina simbólica que tiende a ratificar la dominación masculina en la que se apoya: es la división sexual del trabajo, distribución muy estricta de las actividades asignadas a cada uno de los dos sexos, de su espacio, su momento, sus instrumentos; es la estructura del espacio, con la oposición entre el lugar de reunión o el mercado, reservados a los hombres, y la casa, reservada a las mujeres;

18. Marqués en Norma Fuller, «No unos sino muchos rostros: Identidades masculinas en el Perú urbano», acceso: 06 de mayo, 2019, http://bdigital.unal.edu.co/1403/6/05CAPI04.pdf

19. Se habla de masculinidades (en plural) pues se trata de un panorama diverso y compuesto por múltiples especificidades de los varones. Desde su etnia, nacionalidad, nivel educativo, ubicación geográfica, edad, condición económica y otros factores que hacen diferentes a los hombres. Sabiendo que hay un común denominador que los encaja en una misma realidad de la cultura machista.

20. Pierre Bourdieu, La dominación masculina (Barcelona: Editorial Anagrama, 2004): 23. 
o en el interior de esta, entre la parte masculina, como del hogar, y la parte femenina, como el establo, el agua y los vegetales; es la estructura del tiempo, jornada, año agrario o ciclo de vida, con los momentos de ruptura, masculinos, y los largos períodos de gestación, femeninos ${ }^{21}$.

\section{Representaciones sociales de los arquetipos masculinos}

Los arquetipos se podrían denominar como una serie de tipificaciones, desde una visión mitopoética que definen los rasgos esenciales de la masculinidad. En el texto de Moore y Gillete ${ }^{22}$, llamado La nueva masculinidad: rey, guerrero, mago y amante, se describen estas características que la sociedad patriarcal le ha asignado históricamente a los hombres. El «mago» representa el conocimiento -es decir la racionalidad-; «el guerrero» la fuerza, agresividad, honorabilidad; "el rey» amo del mundo y poseedor de la riqueza, reflejada en el poder económico y, por último, «el amante», el que representa la virilidad sexual de los hombres.

Desde una postura psicoanalítica se podría interpretar que los arquetipos «se refieren a modelos ideales que atraviesan la historia de la masculinidad, desde sus orígenes mismos. Es conveniente subrayar la dimensión ideal que estas categorías discuten, por lo que sus alcances pueden darse en la vida concreta de muchos hombres y también en su mundo imaginario, como imágenes que se han venido cristalizando en la psique masculina desde hace muchos siglos, en la dinámica del inconsciente colectivo jungiano» ${ }^{23}$.

Los arquetipos permiten dotar de objetividad la realidad por medio de representaciones sociales que se proliferan en la vida social cotidiana: las concepciones religiosas, el sistema de creencias de los imaginarios colectivos, el plano político-institucional, la lógica corporativa y de acumulación de capital, son espacios en que los arquetipos masculinos toman validez y se legitiman con el paso del tiempo. Esas representaciones son precisamente las que complejizan romper con patrones opresivos sobre cómo ser hombre, el cual es un tema sumamente relevante para entender las continuidades del modelo de masculinidad tradicional en el ejercicio de la paternidad y cómo, a pesar de los avances en la reivindicación de derechos, incremento de participación laboral femenina, acceso a salud sexual y reproductiva, sigue existiendo una consolidación estructural de la desigualdad sexual.

21. Bourdieu, La dominación, 11.

22. Moore y Gillete en Menjívar, 2007.

23. Moore y Gillete en Menjívar, 149. 


\section{Visión latinoamericana en el estudio de los hombres y sus paternidades}

Olavarría ${ }^{24}$, Romero ${ }^{25}$ y Torres $^{26}$, entre otros, aluden a la reciente producción de estudios sobre masculinidades, motivados por la literatura feminista y por ciertas reivindicaciones sociopolíticas de este movimiento. Es en la década de los setenta cuando surgen, de forma pionera, los estudios sobre los hombres en Europa y Estados Unidos, denominados Men's Studies. Los principales acercamientos se preocupaban por indagar sobre el papel del varón al interior de la familia.

José Olavarría alude que en los años ochenta y en la segunda mitad de los noventa, se empiezan a dar de manera más sólida la acumulación de investigaciones sobre masculinidades. En la última década estos estudios han avanzado de forma creciente, los cuales se han centrado en "cómo los hombres construyen su masculinidad y cómo se asocia ésta con la sexualidad, la reproducción, la paternidad, el trabajo y la violencia. Sus focos principales de atención han sido las identidades masculinas, los procesos subjetivos, los modelos de masculinidad dominantes y las contradicciones y conflictos que enfrentan los hombres en la vida cotidiana y en la relación con las mujeres y otros hombres $»^{27}$.

Vale la pena mencionar diversas organizaciones, centros y colectivos que se han preocupado por abordar la temática, visibilizando la relevancia del trabajo con hombres en la prevención de la violencia, aunado a la lucha por la equidad de género. El aumento a nivel académico de la organización de coloquios, congresos, conferencias y talleres, demuestran el interés en producir conocimiento y discusión al respecto y, sin duda, cada vez son más los profesionales que investigan las masculinidades como eje transversal de los estudios de género. A continuación, se mencionan algunas organizaciones en la región latinoamericana:

- Organización Multidisciplinaria Latinoamericana de Masculinidades (OMLEM), en Argentina.

- Centro de Estudios en Masculinidades y Género, en Uruguay.

- Masculinidades y Equidad de Género (EME), de la Fundación CulturaSalud, en Chile.

- $\quad$ Red de Masculinidad por la Igualdad de Género (REDMAS), en Nicaragua, como parte de la alianza del MenEngage ${ }^{28}$.

24. Olavarría, José, «Los estudios sobre masculinidades en América Latina», Anuario Social Político de América Latina y El Caribe, año 6, FLACSO (2003), acceso: 06 de mayo, 2019, http://es.scribd.com/ doc/20166517/Los-Estudios-Sobre-Masculinidad-en-America-Latina-Jose-Olavarria

25. Raydel Romero, «Por qué hablamos de masculinidades?» (2012), http://www.omlem.com.ar/por_que_hablar_de_masculinidades_3290.htm (web desaparecida).

26. Torres, Laura Evelia, «La paternidad: Una mirada retrospectiva», Revista Ciencias Sociales, 105: 4758, 2004, acceso: 06 de mayo, 2019, https://www.revistacienciassociales.ucr.ac.cr/images/revistas/ RCS105/03Torres.pdf

27. Olavarría, «Los estudios..., 95.

28. MenEngage es una alianza global de organizaciones que lucha en pro de la justicia de género y que los hombres sean parte activa de la solución al problema de desigualdad. 
Las alianzas establecidas con Men Care Global «buscan trabajar en sintonía y colaboración con el movimiento y organizaciones por los derechos de las mujeres -con mujeres, madres, hombres y padres- para identificar y promover comportamientos género equitativos y no violentos en los hombres en el cuidado de niñas y niños y buscando las mejores condiciones para la salud reproductiva y el nacimiento» ${ }^{29}$.

En Costa Rica se ha desarrollado una importante cantidad de estudios provenientes del Instituto Costarricense de Masculinidad, Pareja y Sexualidad (WËM) ${ }^{30}$. Actualmente, el WËM desempeña labores de investigación e intervención con varones, mediante grupos de apoyo con adolescentes, jóvenes y adultos.

Los estudios nacionales sobre el Estado, la paternidad y las masculinidades en el país, coinciden en varios elementos centrales: el papel determinante de instituciones sociales como la religión en la legitimación y reproducción del patriarcado, mediante el rechazo del matrimonio homosexual, aborto terapéutico y educación sexual, lo que refuerza un discurso de mujer-madre abnegada y hombre-autoridad.

Menjívar $^{31}$, Rivera y Ceciliano ${ }^{32}$ y Salas ${ }^{33}$ afirman la trascendencia de construir nuevas paternidades, siendo urgente romper con los patrones de conducta de la masculinidad dominante. «La nueva paternidad habla de un involucramiento más afectivo y activo; es decir, una paternidad que permita involucrar afectivamente con el niño o la niña y participar responsablemente en todas las actividades de los menores $\rangle^{34}$.

\section{Acercamiento metodológico}

\section{Perspectiva metodológica}

Como se mencionó anteriormente, la visión fenomenológica, la lingüística, el acercamiento etnográfico, los estudios de las subjetividades de las personas, los significados de sus acciones y las formas de construir sus realidades, son elementos micro sociales que forman parte de la investigación psicosocial y brindan un aporte sustancial dentro de la disciplina sociológica.

Dichos enfoques permiten dar un vistazo a una realidad global y estructural, ya que en «pequeñas dinámicas» se pueden desprender grandes significados sobre fenómenos sociales globales, los cuales se contrastan con los resultados de la investigación. En el caso de la construcción de las desigualdades entre hombres y mujeres, a partir

29. Campaña de Paternidad MenCare, América Latina (s.f.) «¿Qué es La Campaña de Paternidad Internacional MenCare?», acceso: 06 de mayo, 2019, http://www.campanapaternidad.org/que-esla-campana-de-paternidad $\% 20$ mencare/?fbclid=IwAR 1 mCoOjGluC23rsPznPENDwTFkWbrQ 5E_NNEcxy-QCXaItenU3Vo514s9w

30. WËM significa «hombre» en bribri, lengua indígena de Costa Rica.

31. Menjívar, 2007

32. Roy Rivera y Yajaira Ceciliano, Cultura, masculinidad y paternidad: Las representaciones de los hombres en Costa Rica (San José: FLACSO, 2004).

33. José Manuel Salas, Hombres que rompen mandatos: La prevención de la violencia (San José: Lara Segura \& Asociados, 2005).

34. Rivera y Ceciliano, Cultura ..., 33. 
de la conformación de identidades de género, se puede ver cómo las interacciones cotidianas o las manifestaciones del lenguaje (verbal, corporal y simbólico) dan entrada para hacer interpretaciones sobre la condición que viven hombres y mujeres dentro de la sociedad patriarcal.

Según Weber:

«la investigación psicológico-social implica el detenido examen de diversos géneros individuales, muy dispares entre sí, de elementos culturales con referencia a su interpretabilidad mediante nuestra compresión por vía de revivencia. Con ella, partiendo del conocimiento de las instituciones individuales, aprendemos a conocer espiritualmente en grado cada vez mayor su condicionamiento y significación culturales, más no pretendemos deducir las instituciones a partir de leyes psicológicas ni explicarlas a partir de fenómenos psicológicos elementales ${ }^{35}$.

La sociología comprensiva de Max Weber aporta ideas sugerentes sobre la forma de conocer el fenómeno concreto de las paternidades, pues su aporte metodológico se interesa en realidades complejas y diversas, proponiendo involucrarse con el mundo interpretativo de las acciones sociales.

Por tanto, es pertinente estudiar este tema desde la comprensión del comportamiento de los varones, como resultado de la sociedad fragmentada que les tocó vivir. A la vez, saber que dichos condicionamientos no representan una determinante que resulta imposible de modificar.

\section{Enfoque de investigación}

Es importante tomar en cuenta que la investigación cualitativa comienza como resultado de los cuestionamientos y curiosidades que despierta la vida cotidiana del investigador o investigadora. Este enfoque observa el escenario en que las personas se relacionan entre sí para conocer el entorno socioeconómico, político y cultural en que han vivido, tratando de comprender a las personas dentro sus contextos de referencia. En este sentido, el enfoque cualitativo tiene un carácter holístico y global, ya que involucra las particularidades en la socialización de una persona y también su desarrollo dentro de estructuras sociales determinadas. Esto es fundamental para los objetivos de esta investigación, ya que se explora en las condiciones de vida específicas del joven padre (relaciones familiares, interpersonales, de pares, etc.) y en la estructura social determinada en que han vivido (sistema patriarcal).

«Sus diversas expresiones incluyen hoy en día la inducción analítica, el análisis de textos como crítica, la semiótica, la hermenéutica, las historias de vida, y más recientemente el manejo de archivos, informática y análisis estadísticos, como datos de apoyo a la observación y a la entrevista, o sea, como posibilidad de triangulación $»^{36}$.

35. Max Weber, Ensayos sobre metodología sociológica (Buenos Aires: Amorrortu Editores, 1978), 78.

36. José Antonio Camacho, La construcción del conocimiento en la investigación cualitativa (2013), acceso: 06 de mayo, 2019, http://www.revistas.una.ac.cr/index.php/repertorio/article/view/7976 
El tipo de investigación es descriptiva y exploratoria; la primera pues uno de sus objetivos es conocer la caracterización educativa, contextual y familiar de los jóvenes entrevistados y así comprender sus realidades y comportamiento de acuerdo con un indicador circunstancial; la segunda es por el carácter de indagación documental que tuvo el estudio, en donde la exploración de datos e investigaciones sobre el tema permitió conformar un estructura teórica y epistemológica sólida para darle validez al problema planteado.

\section{Entrevista en profundidad: conociendo experiencias de vida}

El instrumento de investigación principal fue la entrevista en profundidad, la cual se utilizó con la rigurosidad pertinente para darle un uso provechoso y asertivo. Al tratarse de una temática sensible que involucraba vivencias de la infancia, relaciones familiares, vínculos afectivos, experiencias satisfactorias, dolorosas y contradictorias de los entrevistados, resultó ser un reto al momento de interactuar con los jóvenes padres entrevis$\operatorname{tados}^{37}$. Ante esto se previó y estudió con detalle los aportes que el enfoque cualitativo aportaba, aspectos como el lugar de la entrevista y la empatía durante la entrevista ${ }^{38}$. Tal como se expresa en la investigación, un elemento enriquecedor fue el carácter de complicidad o compresión mutua entre investigadora y joven padre, por la cercanía de edades y experiencias.

Esta herramienta, por su carácter cualitativo, tiene como característica entablar un vínculo amigable y cómodo con la persona entrevistada; con el fin de propiciar una comunicación fluida y así, un aporte enriquecedor a la investigación. Fue pertinente contar con una guía de preguntas sobre los diversos temas que se deseaban conocer; sin embargo, un aspecto determinante fue el surgimiento de historias, anécdotas y situaciones que aportaron de gran manera a la dinámica entrevistadora- sujeto. Particularmente, en esta investigación con padres jóvenes, un aspecto beneficioso es la interacción entre jóvenes (investigadora-investigado); por lo tanto, se estable un diálogo abierto y basado en reciprocidad.

Sin embargo, es menester considerar los posibles sesgos que se presentan, Fuller señala al respecto de su investigación con hombres peruanos: «No pretendo con ello que el contexto no los influenciara; cada entrevistado fue creando una nueva versión de su vida como varón para narrársela al entrevistador, pero ésta es una distorsión inevitable en una investigación centrada en el relato de los informantes» ${ }^{39}$.

37. Ante dicha susceptibilidad en las narraciones, es importante el carácter de confidencialidad en las identidades de los jóvenes entrevistados y las personas mencionadas en sus narraciones. Por esto, en los extractos de los relatos de vida se citan nombres falsos.

38. En cuanto a la empatía, se entiende como el tipo de interacción que se estableció con los entrevistados, el inclinarse por una conversación amena, no unilateral, mediante el compartir de experiencias, que fue un aspecto clave para obtener una mayor apertura de los jóvenes padres. El procurar trasmitir comodidad y confianza sobre los temas conversados, sin duda resulta ser una estrategia fundamental en las entrevistas en profundidad.

39. Fuller, s.f.: 270. 


\section{Paternidades en jóvenes costarricenses: principales hallazgos}

A continuación, se observa el proceso llevado a cabo para realizar el respectivo análisis de los hallazgos.

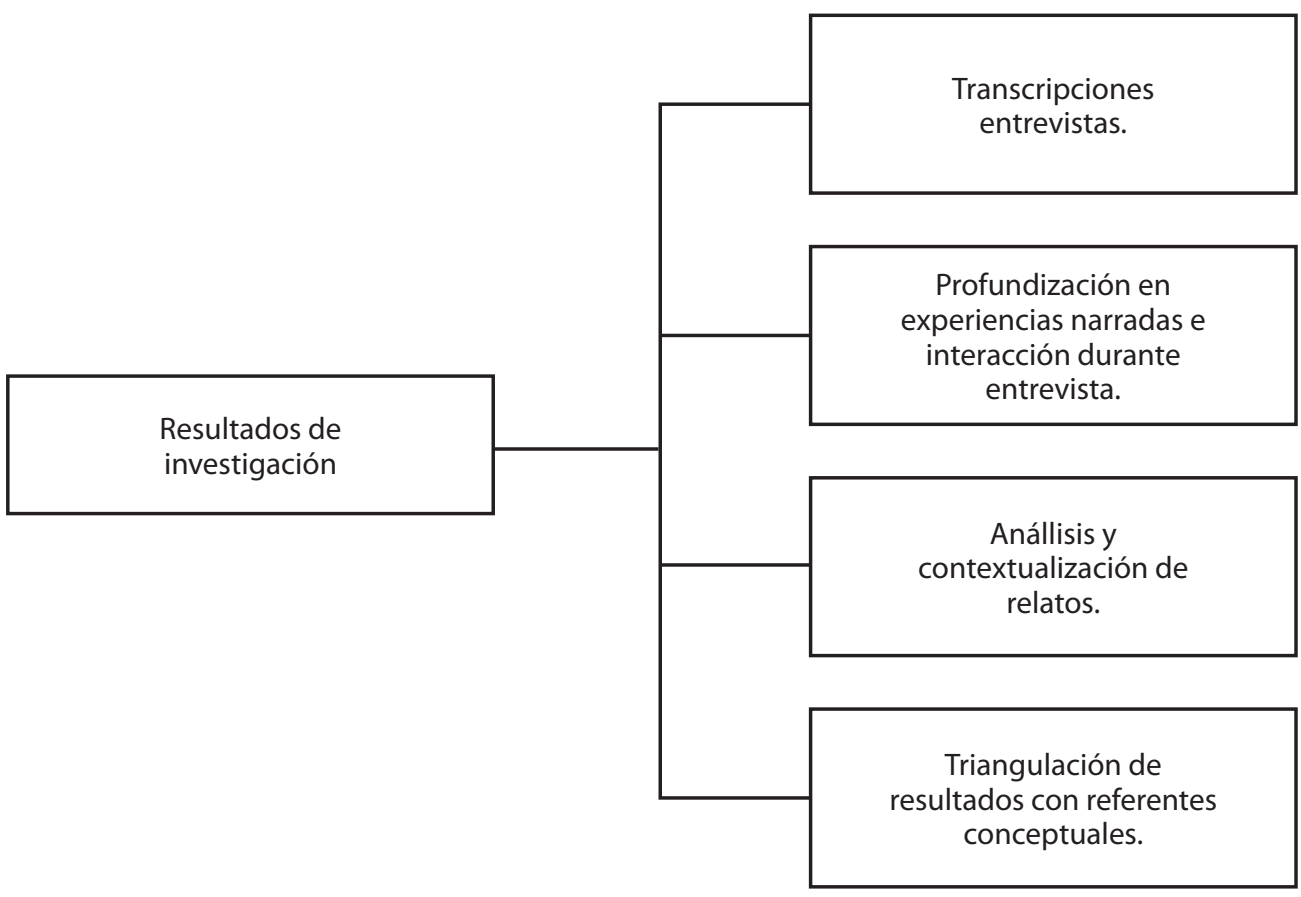

Con el análisis de las transcripciones de las entrevistas en profundidad, los testimonios de vida, relatos y producto de la interacción con los jóvenes, se hizo un bosquejo de la información empírica. Por medio de esta recopilación, sus comparaciones y categorizaciones, se desprenden significantes claves para explicar el fenómeno de la paternidad, en relación con la construcción social de las masculinidades.

Previo a profundizar en los resultados de la investigación, resulta necesario señalar las características de los jóvenes padres entrevistados, como se expone en la figura de la página 27.

Los estudios sobre el tema ayudan, de manera sustancial, a comprender el porqué del comportamiento de los hombres en diferentes espacios: el laboral, económico-productivo, cultural (prácticas en que los hombres se ven implicados con mayor frecuencia, como la ingesta de licor, deportes o pasatiempos riesgosos, aquellas prácticas del espacio recreativo y lúdico) y las repercusiones de esos modelos de dominación en las afectividades de los varones. Múltiples insumos podrían mencionarse del vínculo entre ser hombre y padre, los cuales caben puntualizarse a continuación. 


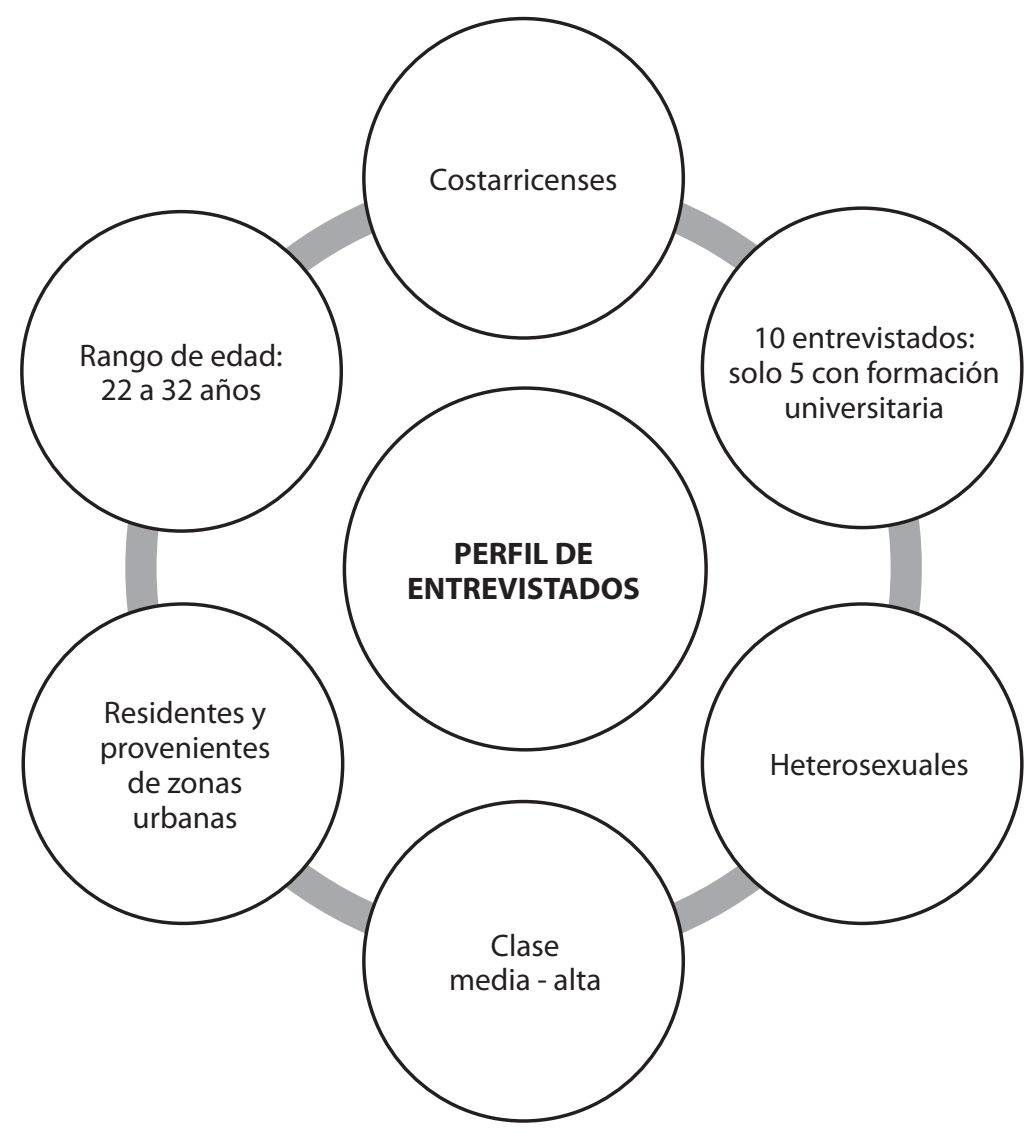

\section{Relación paternal: experiencias de vida, aprendizajes y mandatos}

A pesar de que algunos jóvenes entrevistados han vivido con sus padres o mantienen cierta relación con ellos, la mayoría manifestaron sentir limitantes en la relación con su padre desde la niñez, en especial por la falta de afecto y atención. Por lo tanto, a pesar de proveer los recursos para su subsistencia y convivir cierto tiempo con ellos, no percibían su presencia de una manera placentera y plena, ya que expresaban sentir ciertas inquietudes o vacíos en el vínculo que mantenían con ellos.

Este aspecto fue central en la investigación, pues explica la forma en que los jóvenes han asimilado esas relaciones y los efectos en sus actividades como padres. Es un elemento que influye en el moldeamiento de sus subjetividades y maneras de relacionarse con los demás, especialmente con sus hijas/os. 
A continuación, algunos de sus relatos sobre este ámbito de sus vidas:

«Sí, digamos de los 11 a los 15, di yo me escapaba de la casa, buscaba mi autonomía, mi independencia, de hecho, en mi familia todo era muy conflictivo, entonces no quería estar ahí. Mi mamá y mi hermana peleaban mucho» ${ }^{40}$.

«Sí, era como muy autosuficiente e independiente. Porque mi papá se fue de la casa cuando yo tenía 6 años, entonces mi mamá se tuvo que poner a trabajar. Y ya ella trabajando, yo y mi hermano, bueno más que todo yo, que era el mayor de los que quedamos de la casa, porque los demás eran más mayores. Entonces ya era empezar a hacer quehaceres domésticos» ${ }^{41}$.

Además, Luis comentó cómo una situación de agresión por parte de su padre marcó algo determinante en su vida: la falta de interés por los estudios.

«Parte de lo que yo... no avanzo en el estudio, fue cuando yo estaba en primero y estaba haciendo una tarea y él venía de la calle siempre malhumorado y yo no entendía. Y me preguntó por qué estaba llorando y mi hermana le dijo porque no entendía (la tarea), entonces llegó y me golpeó en la cabeza, entonces no sé. Él nunca me había golpeado ni nada, entonces yo me pregunté ‘'Por qué nunca me ha golpeado ni nada y ahora que estoy con esto, él lo hizo por eso?' Entonces fue por eso que no me gustaba el estudio, porque estoy con algo que es nuevo para mí y llega y me agrede» ${ }^{42}$.

Estas vivencias familiares expresadas por los jóvenes definieron parte de sus deseos por querer mejorar, o bien, no repetir las malas experiencias que tuvieron. Cuando se les pregunta sobre los valores y enseñanzas que quisieran inculcar en sus hijas/os, manifiestan:

«Lo mismo que me inculcaron a mí en realidad, yo siempre he dicho que mi mamá conmigo hizo muy buen trabajo siento yo, entonces yo le he dicho a mi esposa que yo quiero ser el mismo padre como fue mi mamá para mí y yo para ella» ${ }^{43}$.

«Tiene que ir conociendo, porque... ahora va para sexto eso no es tanto, pero en el cole él va viendo esas cosas, entonces más que todo, como ese cuidado, como irlo guiando, tratando de darle una perspectiva más humana de lo que hay afuera ${ }^{44}$.

«Que sea una persona independiente en el buen sentido, que sea una persona responsable, que sea una persona que no requiere ir a la iglesia o cosas así, para verdaderamente reproducir valores. Como el respeto, la responsabilidad, este... la cuestión de ambiente para mí es muy importante, verdad. Por ejemplo, que Felipe me bote una basura en algún momento, eso va a ser completamente inaceptable. Igual que le falte el respeto a alguna mujer, igualmente a algún hombre, a algún indigente... o al presidente ¿Me explico? $\rangle^{45}$.

\footnotetext{
40. (Álvaro, 26 años)

41. (Luis, 28 años)

42. Luis

43. (Manuel, 28 años)

44. (Josué, 30 años)

45. (Sergio, 25 años)
} 
Todos los padres entrevistados coinciden en la importancia de fomentar valores como el respeto, tolerancia, integridad y comportamiento humano hacia los demás. Lo cual fue unos de los rasgos en común que se presenció en las conversaciones entabladas con los padres y que, sin duda, se aleja de un modelo dominante de ser hombre o, al menos, es parte de la intención que ellos expresan. De la mano con la idea de no querer repetir ciertas conductas vivenciadas con sus padres desde la infancia, reforzado en la expresión «no quiero ser como fue mi padre», la cual aporta un indudable mensaje semiótico en esta investigación.

\section{Vivencia de la paternidad: del disfrute a una participación secundaria}

En los relatos de vida de los jóvenes entrevistados se aprecian varias características semejantes con respecto al ejercicio de la paternidad, los significados en sus vidas y cómo han influido las exigencias de la sociedad patriarcal en su quehacer como padres.

\section{Mandato de padre proveedor}

Una de las bases teóricas de esta investigación se centra en la relación de las categorías de masculinidad dominante-poder económico. La concepción de éxito en los hombres es asociada en gran parte al factor económico, a sus logros como generador de dinero, como productor económico y figura de supremacía y control. Estas características son concebidas socialmente como símbolo de estatus social y, en los varones, como atribución de hombría, poder, independencia y honor. Estas han tenido un valor distintivo en la construcción de identidades masculinas, es decir, desde la infancia las personas menores de edad crecen y aprenden la idea de obtener recursos económicos por medio de la obtención de bienes materiales como un automóvil, casa, etc.

Una tendencia apreciada en los relatos, experiencias y percepciones de los jóvenes padres tiene que ver con la importancia que estos le dan al aporte económico como una de sus responsabilidades esenciales desde el momento que se enteraron de que iban a ser padres. De inmediato, hicieron las modificaciones en su estilo de vida para encontrar trabajo o mejorar sus condiciones laborales, algunos abandonaron sus estudios universitarios por ese motivo.

«Actualmente... bueno, no sé si es temor, es envejecer o tal vez llegar a cierta edad y buscar trabajo y por tener cierta edad no consiga. Un trabajo que digamos pueda mantenerlo a él, faltan algunos años» ${ }^{46}$.

«De hecho, el único miedo que tengo es quedarme sin trabajo, porque depende de mi familia» ${ }^{47}$.

«El trabajo es otra preocupación verdad, sabe uno... bueno, uno trabaja por contrato entonces después de esto, cuando este trabajo se termine, tiene que ver uno qué pasa ${ }^{48}$.

46. (Josué, 30 años)

47. (Pablo, 25 años)

48. (Ricardo, 28 años) 
Evidentemente las necesidades económicas forman parte de la llegada de un hijo/a y estas deben ser solventadas, el cuestionamiento recae en la preocupación existente de los padres en cumplir con esta función por encima de tareas básicas de cuido en el aseo, alimentación, enfermedad, enseñanzas, juegos y presencia activa en la vida de los menores. De esta forma lo interpreta Torres:

«Parece ser que los varones confunden la custodia (guarda física de los hijos menores no emancipados dictaminada en una sentencia, donde su ejercicio tiene implícito el otorgamiento de la patria potestad) con la patria potestad. Quizás esto lleve a entender la razón de que muchos de los varones se desentiendan de los hijos, al considerar que la patria potestad le fue otorgada a la madre y que a ellos les han quitado la responsabilidad en la crianza, siendo su única participación la pensión alimenticia, pero debe insistirse que en general la misma sea otorgada a ambos progenitores ${ }^{49}$.

Sin duda, cuando se habla de responsabilidad en la paternidad, generalmente tiene una connotación asociada al soporte económico y, en la institucionalidad costarricense, prevalece una perspectiva de responsabilidad paterna primero con el reconocimiento en el Registro Civil de los hijos/as y, posteriormente, como un deber de los hombres de dar el sustento a estos. Esa es la misión de herramientas jurídicas como La Ley de Paternidad Responsable y la Ley de Pensiones Alimentarias, las cuales han representado un papel importante en la protección de la niñez y de las madres que han tenido que asumir solas el cuido de los menores.

La mitad de los padres entrevistados no viven diariamente con sus hijas/os, debido a la separación de pareja. Solo un padre vive con su hijo, producto de la decisión del menor. De ellos, únicamente uno paga pensión alimentaria; los demás asumen parte de la manutención en conjunto con las madres. Solamente un padre optó por una modalidad de pensión voluntaria:

«No, bueno actualmente yo. Y luego hasta un año, di ella empezó con cosas que no me parecían, entonces... digamos yo le daba una pensión voluntaria, bueno todavía se la doy, una pensión de cosa mía, solo de alimentación.»

_ ¿Pero pensión de que se hablara o por medio de ley?

«No, por cosa mía. Digamos yo antes le entregaba el dinero en la mano, para que ella le comprara las cosas. Pero, por unos problemas que pasaron, un juez de familia me recomendó que pusiera pensión voluntaria, hasta que vi que teníamos otros amigos que tenían una chiquita como de 5 años, y siempre estuvo ahí. Y lo quisieron perjudicar y le pusieron una pensión como de 4 millones. Entonces yo me puse a pensar que no quiero eso, porque aparte que soy responsable, entonces opté por el método de depositar en el banco la pensión ${ }^{50}$.

49. Torres et al., «Paternidad y ruptura familiar», 281.

50. (Luis, 28 años) 
De acuerdo con el carácter dominante de «ser hombre», hay un mandato social que demanda la represión de ciertas emociones, principalmente aquellas que manifiestan vulnerabilidad, fragilidad o dependencia hacia los demás. Al mismo tiempo, algunas muestras de amor y cariño se dan bajo ciertas circunstancias (como en espacios privados, sin exhibir afecto públicamente, con una palmada en la espalda-como comentó uno de los informantes-o bajo el efecto de sustancias como el alcohol). Cuando se les preguntó a los jóvenes sobre la demostración de afecto de sus padres, algunos respondieron lo siguiente:

— ¿No era muy afectivo?

«No, de lo que yo recuerdo no. Cuando llegaba borracho sí, lo agarraba a uno y lo estripaba $\operatorname{todo}^{51} \gg$.

_ ¿Cómo era la relación con su padre en la infancia-adolescencia?

«Bueno, fue muy buena. Bueno hasta después dejó de tomar, dejó de fumar cuando nació mi hermano mayor. No, no, muy buena, nosotros íbamos y mi papá se echaba las birras y así, y parecía que manejaba mejor borracho».

_ ¿Pero no era agresivo cuando llegaba así?

«Ajá, sí, exactamente. No, más bien era al contrario, él llegaba a escuchar música, a tomarse un traguito de whisky ahí y estábamos nosotros y ‘los amo mucho' y toda esa vara ${ }^{52} \gg$.

En algunos testimonios de los entrevistados, se dejó ver la marca de esa escasa afectividad de sus padres en la formación de sus personalidades y en la relación con sus hijas/os.

«En el caso de no recibir (afecto), bueno mi papá. Bueno mi mamá tampoco es como muy afectiva, entonces tal vez como por esa parte un poquito y, aun así, a mí me cuesta un poco con Andrés, por eso mismo. Porque como no recibía. O sea, sí lo hago, pero lo admito, me cuesta bastante» ${ }^{53}$.

«Yo era muy hermético, el afecto no era... en esa época el afecto no era lo mío» ${ }^{54}$.

A pesar de que la mayoría de los jóvenes comentan haber recibido muestras de cariño aisladas por parte de sus padres, se pudo evidenciar que ellos han practicado lo contrario en sus experiencias como padres. Esto permite aseverar que «si bien se reconoce dentro de las características identitarias en el hombre, la invalidación de la expresión de sentimientos y dificultad para expresar sus emociones, también hay que reconocer y tener cuidado de no caer en una simplificación o generalización estereotipada al señalar que los hombres han perdido, en el camino de la socialización, la capacidad de encontrarse

51. (Luis, 28 años)

52. (Sergio, 24 años)

53. (Josué, 30 años)

54. (Álvaro, 26 años) 
en sí mismos [sic] y de expresar el dolor o la ternura, muy especialmente en sus relaciones con mujeres o niños» ${ }^{55}$.

Esto se ve reflejado en las narraciones de los padres:

«Yo antes, me acuerdo, yo me acostaba en la cama, veía tele y nada me motivaba ni levantarme ni nada así. Ahora sí, yo paso activo, siento como que me trajo a la vida de uno, ya la vida que nunca tuve... con Matías uno siente que de verdad tiene que levantarse todos los días a trabajar y hacer bien las cosas y todo $»^{56}$.

«Entonces sí, siempre ando con él, igualmente no me gusta dárselo a nadie. A raíz de que yo estoy con mi bebé una vez a la semana, verdad. Entonces yo quiero estar con él, el tiempo que esté, todo verdad» ${ }^{57}$.

En el caso de Sergio, debido a la separación con la madre de su hijo, por indicación de ella solamente lo puede ver un día a la semana. Para él, esta situación ha sido muy difícil, por lo que disfruta cada momento que puede convivir con su hijo.

«Entonces yo veo a mi hijo, lo recojo, le alisto su chuponcito, se toma su chupón. De repente, si es un domingo que mis papás van a la iglesia, yo llego con él y todo el mundo viendo a Felipe, la familia verdad. Salimos un rato, vamos al Mall, de hecho, él tiene un carrito, entonces lo ando por acá, lo llevo al otro play por mi casa. Le alisto una comida, verdad».

— ¿No se queda él a dormir a su casa?

«No, porque... Y no es cuando ella considere (madre del niño) que hasta que él hable, es como...».

\section{—¿Qué pueda decidir?}

«Exactamente, hasta que él pueda decir que algo le está pasando (risas); no estoy de acuerdo, pero también lo comprendo, tiene razón la verdad, tiene razón. Y digamos, después paso el día con él, él se come sus verduras, de hecho le encanta comer bien. Se echa un sueñillo en la tarde, igualmente un chuponcito, después una merienda, desde ahí nos vamos a las 6, 7 de la noche, e igual lo voy a dejar y llegamos hora, hora y media después».

En general, los jóvenes expresan su sentimiento de satisfacción de pasar tiempo con sus hijas/os, formar parte de su educación, cuidados, necesidades, etc. No obstante, tal como lo indica el título de este apartado, hay una vivencia de disfrute de la paternidad pero a la vez asumen, por decisión propia o por indicación de la madre de los menores, un rol secundario en el cuido y crianza.

55. Sánchez en Menjívar, «Hombres inventados...», 145

56. (Carlos, 30 años)

57. (Sergio, 25 años) 
Siguiendo con la idea anterior, hay una extensa explicación detrás del porqué las exparejas de los jóvenes entrevistados se quedan de forma automática y sin cuestionamiento con la custodia de los menores, ante la separación de pareja. Y es que «la gran influencia social, cultural y religiosa que ubica a la mujer como la responsable del hogar y la crianza ha hecho que se le conciba como el pilar de la familia, dejando de lado la función paterna» ${ }^{58}$.

Figueroa, en su texto denominado Paternidad, mortalidad y salud: jes posible combinar estos términos?, articula de forma atinada la exclusión social y simbólica del hombre de los procesos de involucramiento con sus hijas/os, aspecto que está estrechamente ligado a la valoración cultural otorgada a las madres como las figuras trascendentales en la vida de los menores, relegando a los padres a un papel secundario, de ahí el motivo por el cual la ausencia paterna no es tan recriminada como la ausencia materna.

«Existen desde hace tiempo 'servicios de salud materna e infantil', algo que difícilmente se nombraría pensando de alguna manera en la experiencia de la paternidad. Podríamos revisar a detalle las representaciones sociales vinculadas al ejercicio de la maternidad y tratar de entender desde ahí las razones por las cuales dichos servicios son descritos de esa forma, para lo cual sería más que evidente el papel tan importante que juega el hecho de que el cuerpo de las mujeres puede vivir un embarazo y el vínculo de esto con las transformaciones fisiológicas y los riesgos asociados a dicho embarazo; pero a la vez, podríamos reconstruir algunos de los significados valorativos que ello tiene, tanto para diferentes actores e instituciones sociales, como para los proyectos de vida y de identidad de género de las mismas mujeres ${ }^{59}$.

Los testimonios de los padres entrevistados dejan ver esta realidad, pues, casi de manera naturalizada, se le adjudica a la madre su permanencia con los hijos/as ante una separación de pareja. Esto muchas veces no se somete a discusión, ya que se adapta a los mandatos de la sociedad patriarcal que asigna un papel prioritario a la maternidad sobre la paternidad. Recapitulando los insumos teóricos, esto se relaciona directamente al papel de las mujeres como reproductoras y cuidadoras, mientras que el rol de los hombres es de productores y proveedores. Esta separación ha incidido en el papel relegado socialmente de los hombres como padres-cuidadores.

\section{Grupos de pares, consumo de alcohol y drogas: reinventándose el involucramiento paterno}

Retomando los rituales de iniciación acuñados por Gilmore, los varones se encuentran en círculos sociales que les impulsan a asumir determinadas conductas para reafirmar su masculinidad. «Los grupos de pares son uno de los ámbitos más opresivos para la producción y regulación de las masculinidades ${ }^{60}$. $«$ Los jóvenes son forzados por sus

\footnotetext{
58. Torres et al., «Paternidad y ruptura familiar», 281.

59. Juan Guillermo Figueroa, «Paternidad, mortalidad y salud: ¿Es posible combinar estos términos?», IV Coloquio Internacional de Estudios sobre Varones y Masculinidades, Montevideo, 2011.

60. Connell y Haywood en Fuller, s.f.: 271.
} 
compañeros a ajustarse al modelo de masculinidad del grupo. Estas presiones, a su vez, desempeñan un papel importante en la constitución de la identidad de género porque marcan los límites admisibles de conducta que permiten a los jóvenes visualizar lo que debe ser la masculinidad apropiada» ${ }^{61}$.

Según datos del Ministerio de Salud de Costa Rica, en el país, los índices de suicidio son notoriamente más elevados en hombres que en mujeres. Este panorama también se refleja a nivel mundial. Una de las dimensiones que motivan al suicidio, según estos datos, es la ingesta de alcohol y otras sustancias psicoactivas dentro de estos consumidores. El IAFA ${ }^{62}$ indica que los hombres son mayoría en el consumo de alcohol. Estas tendencias se explican en «el temor a desvirtuarse o desviarse de ese camino puede perpetuar un encerrarse en sí mismo. Por tanto, este modelo no sólo sirve para justificar su desarrollo emocional conforme a lo que representa el verdadero hombre, sino también le aboca a desorientarse, deprimirse y violentarse si no lo consigue emular, sin saber qué otro rol asumir» ${ }^{63}$.

Algunos padres entrevistados narran que, durante su adolescencia, y parte de la juventud, cayeron en el consumo desmedido de alcohol y otras sustancias como marihuana, cocaína, LSD y éxtasis.

«Sí, sí, creo que fue por el lugar donde crecí, uno crece rodeado de mucha droga, entonces era cuál era el más carga y todo eso» ${ }^{64}$.

«Y a mí me ha costado mucho, hasta ahora... me ha costado mucho surgir porque siempre andaba de fiestero, metido como en vicios, en cosas que nada que ver. Entonces a mí me ha costado mucho superar esas cosas, desde que estoy joven he tratado de superarlas, hasta el día de hoy» ${ }^{65}$.

Debido a la llegada de la paternidad, los jóvenes que se encontraban involucrados en consumo de alcohol y drogas hicieron cambios decisivos en sus vidas para hacerle frente a la nueva dinámica.

«Di un cambio de vida, totalmente. Digamos de empezar a dejar la fiesta, porque fue un proceso bastante fuerte. Porque fueron muchos años de andar de fiesta y muchas adicciones muchas varas. Entonces fue dejar eso, por ella (hija) y por mí» ${ }^{66}$.

«Es vacilón porque es una sensación que siento hasta ahora con él, cuando lo veo salir de la casa y se tira y pela una risilla y así, es conocer el verdadero amor» ${ }^{67}$.

\footnotetext{
61. Fuller, N, s.f.: 271.

62. Instituto sobre Alcoholismo y Farmacodependencia, IAFA «VI Encuesta Nacional 2015: Consumo de drogas en Costa Rica» (San José: IAFA, 2018).

63. María Guadalupe Vélez Bautista, «Violencia, cuerpo y masculinidades El caso de los bailarines de ballet clásico» (2015), acceso: 06 de mayo, 2019, https://www.researchgate.net/publication/315081460_ Violencia_cuerpo_y_masculinidades_El_caso_de_los_bailarines_de_ballet_clasico

64. (Ernesto, 32 años)

65. (Fernando, 28 años)

66. (Luis, 28 años)

67. (Sergio, 24 años)
} 
«Un cambio grande, más que todo de responsabilidad. En realidad, uno deja unas cosas para llenarlas por otras, que no tienen valor ${ }^{68}$.

Con esto, se pudo percibir en los relatos de vida de los jóvenes padres entrevistados, un interés en querer hacer un cambio en sus vidas, tanto a nivel laboral, profesional y en el crecimiento individual, con el fin de ser una mejor persona para sus hijas/os.

\section{Nuevas paternidades: rupturas del modelo tradicional}

Un «padre nuevo» o que rompe con una paternidad tradicional es aquel que no limita su papel a la proveeduría o a una presencia distante, sino que desea formar parte importante en la vida de su hijo o hija, por medio de las enseñanzas, crianza y cuidados.

Ceciliano y Rivera apuntan que «la nueva paternidad habla de un involucramiento más afectivo y activo; es decir, una paternidad que permita involucrar afectivamente con el niño o la niña y participar responsablemente en todas las actividades de los menores ${ }^{69}$.

En las entrevistas realizadas a los jóvenes padres, se pudo constatar que existe cierto cambio con respecto a este modelo de padre tradicional, pues hay un profundo interés, en la mayoría de ellos, por ser una figura de apoyo, ternura y compresión para sus hijas/ os. No obstante, la separación de pareja ha significado una participación parcial en la crianza y cuidados de los menores, pues se le relega un espacio de finales de semana para estar presente, lo cual tiene dos componentes: sus exparejas y madres de sus hijas/os, asumen de manera automática la convivencia con las personas menores de edad y, además, hay una actitud de conformidad y aceptación de la situación por parte de los padres. Ante esta tendencia, surge la pregunta: ¿Por qué estos padres interesados en permanecer con sus hijas/os no luchan para obtener una custodia compartida? Esta interrogante deja abierto el amplio camino por recorrer en el cambio de paradigmas sobre roles de género y sobre la trascendencia de la presencia activa tanto de madre como del padre, en el crecimiento de una niña o niño.

No obstante, sí se pudo comprobar un factor que ha incidido en la constitución de una nueva paternidad, y es el incremento creciente de las mujeres en el mercado laboral. Casi todas las madres de los hijos/as de los padres entrevistados, son profesionales, posicionadas laboralmente y con independencia económica. Este hecho se ve reflejado a nivel regional, según el Informe del Estado de Paternidad en América Latina y Caribe, «la participación laboral femenina para la región alcanzó al 53\% en 1990, esta se incrementó hasta el 68\% 25 años más tarde. Ahora bien, a pesar de este crecimiento, el avance ha sido insuficiente para cerrar la brecha con los hombres, cuya tasa de participación permaneció prácticamente constante a lo largo de dicho periodo - cercana al 95\% - y son quienes reciben, además, mayores salarios» ${ }^{70}$.

68. (Pablo, 25 años)

69. Rivera y Ceciliano, Cultura ..., 33 .

70. Estado de la Paternidad: América Latina y El Caribe MenCare, «Informe del Estado de Paternidad en América Latina y Caribe» (2017), acceso: 06 de mayo, 2019, http://www.campanapaternidad.org/ estadodelapaternidadlac2017/ 
Además de la desigualdad salarial, sigue recayendo sobre las mujeres la atención y crianza de las personas menores de edad. En el estudio realizado con estos jóvenes padres, se logró evidenciar esta situación, tanto en los que viven con su pareja e hijo, como en los que no. Ante esto, es necesario concebir la paternidad afectiva e involucrada, al hombre comprometido totalmente con los cuidados del menor, no reducir sus actividades al plano lúdico, sino a las necesidades básicas como limpieza, cambio de pañales, preparación de alimentos, cuido en enfermedad, etc.

\section{Conclusiones}

A continuación, se puntualizan las conclusiones principales que se desprenden del trabajo de investigación realizado.

- Relevancia de abordar las paternidades. Tal como se indica en el Informe del Estado de Paternidad en América Latina y Caribe, «la participación positiva de los hombres en el curso de la vida de sus niños/as puede tener efectos profundos en el bienestar no solo de sus hijos/as sino de sus familias, comunidades y naciones. Debemos alentar a los hombres a asumir esta responsabilidad y apoyarlos para hacer de esto una realidad $»^{71}$. Esto comprueba la trascendencia de los estudios sobre paternidad, pues las personas menores de edad que son socializados por hombres afectivos, involucrados y comprometidos con la crianza, transmiten una serie de enseñanzas y valores que son cruciales para el posterior desenvolvimiento de esos menores. Los resultados de la investigación con el grupo de jóvenes padres costarricenses, dejó evidencia de dicha aseveración: aquellos jóvenes que sufrieron abandono paterno, situaciones de violencia o un involucramiento distante y parcial por parte de sus padres desde la infancia, desencadenó una serie de conductas en la adolescencia (consumo de sustancias, dificultad para manejar las emociones y una negación a querer repetir el rol de su padre).

- Necesidad de estudiar las masculinidades en la prevención de la violencia de género. A partir de la exploración teórica y contextual se identificaron los temas pendientes y áreas por trabajar; la necesidad de concebir los estudios de los hombres como eje transversal, en los intentos por la igualdad, sigue siendo un reto. Esto porque en algunos espacios siguen sin considerarse, o bien, se estudian de una forma aislada y sin darle la relevancia pertinente a la necesidad de comprender las razones detrás del comportamiento masculino.

- Peso de la estructura patriarcal. La mayoría de los entrevistados hicieron cambios en su vida personal, en función de procurarle mayor bienestar a sus hijas/os, como el caso de la lucha por superar problemas de adicción a drogas y alcohol, el cambio de círculo de amistades y las actividades de esparcimiento que anteriormente realizaban. Con esto, a pesar de que los jóvenes entrevistados se preocupan por involucrarse en la vida de sus hijas/os, hay diversas circunstancias que limitan esa participación, en especial el aspecto estructural e ideológico que delega a la mujer ser

71. Estado de la Paternidad..., 2017. 
la figura de cuido y crianza. Además, sigue prevaleciendo el tema de la hombría, en síntesis «sentirse hombre» por medio de diferentes conquistas (sexuales, económicas, deportivas, etc.).

- Ruptura con el modelo de hombre no afectivo. Se puede percibir un sentimiento de disfrute de pasar tiempo con los menores, especialmente en los espacios recreativos, de expresar cariño, atención y muestras físicas de afecto (besos, abrazos, caricias). También, se puede afirmar que hay cierta tendencia en los jóvenes a entablar relaciones amorosas más horizontales, en donde hay apoyo o entusiasmo en los logros de la pareja.

- Urgencia de nuevo paradigma. La investigación permitió el hallazgo de estudios, artículos y acercamientos que continúan reproduciendo los roles sexistas sobre madre y padre. Por ejemplo, se identifica un manejo del lenguaje que relega a un papel secundario a los padres, aún se habla de «los hombres deben ayudar más a las mujeres...» o «la participación de los hombres en la casa», como si se tratara de una colaboración y no un quehacer protagónico y activo.

\title{
ABSTRACT
}

\section{Young Costa Rican fathers: changes and consistency in traditional masculinity}

\begin{abstract}
This article aims to evidence the close relationship between the construction of masculinities and the ways fatherhood is lived and exercised. This relationship was deeply studied in the dissertation called Exercise and conception of fatherhood in two groups of young Costa Rican fathers: changes and consistency in traditional models of masculinity; the results are very helpful in understanding why men exercise parenting in a certain way, how it influences their daily life and emotions, and the role of patriarchal society in their learnings, belies, and behaviors. Part of the relevance of this research is to offer input to future studies and interventions involving young fathers and dominant masculinity. This comes at a time when at the institutional and governmental level it has become clear the need to reconsider «responsible fatherhood» from a new paradigm that focuses on caring and commitment with childrearing. This also results in questioning the focus and impact of the Responsible Parenthood Law, the Law of Child Support, and the Code of the Family through an integral analysis of their content taking into account the legal implications of those laws in the lives of many fathers. This research brings to the table many aspects of the reality of the young men interviewed, and so it results in a rigorous understanding of their masculinities and how they have been consolidated.
\end{abstract}

Key words: Men, childrearing, father involvement, cultural context, social research.

RÉSUMÉ

\section{Jeunes pères costariciens: changements et continuités de la masculinité traditionnelle}

Cet article met en évidence l'étroite relation entre la construction des masculinités, les manières de vivre et d'exercer la paternité. Ce lien a été recherché de forme approfondie dans le mémoire intitulé «Exercice et conception de la paternité en deux groupes de jeunes pères costariciens : changements et continuités des modèles de masculinité traditionnelle». Les résultats ont permis de comprendre les raisons des hommes pour assumer leur paternité de certaine manière et l'influence de celle-ci dans la vie quotidienne, l'émotivité, et sans doute, le rôle de la société patriarcale dans leurs apprentissages, leurs croyances et leurs comportements. Par conséquent, cette 
recherche vise à fournir des lignes et des apports aux études et aux interventions prochaines sur le travail avec des jeunes pères et leur relation avec la masculinité dominante. D'autre part, il y a une urgence de repenser la «paternité responsable» conçue au niveau institutionnel-gouvernemental, dès un nouveau paradigme centré dans l'implication affective et engagé à l'élevage et à la garde des enfants. Ceci met en question l'approche et l'impact de la Loi de Paternité Responsable, de la Loi de Pension Alimentaire et le Code de famille à travers une analyse intégrale de leur contenu et en connaissance de l'usage juridique de ces lois dans la réalité de beaucoup de pères. Cette recherche met en balance multiples aspects qui conforment la paternité des jeunes interviewés, et au même temps offre une rigoureuse compréhension de leurs masculinités et la manière dont elles ont été consolidées.

Mots-clés: Hommes, élevage, paternité, participation des pères, contexte culturel, recherche sociale.

\section{Bibliografía}

Badinter, Elisabeth. XY La identidad masculina. Madrid: Alianza Editorial, 1993.

Berger, P. y Luckmann, T. La Construcción Social de la Realidad. Madrid: Amorrortu Editores, 1968.

Bourdieu, Pierre. La dominación masculina. Barcelona: Editorial Anagrama, 2004.

Butler, Judith. Mecanismos psíquicos de poder: teorías de la sujeción. Valencia: Ediciones Cátedra, 2001.

Camacho, José Antonio. La construcción del conocimiento en la investigación cualitativa. Acceso: 06 de mayo, 2019. http://www.revistas.una.ac.cr/index.php/repertorio/article/view/7976

Campaña de Paternidad MenCare, América Latina. «¿Qué es La Campaña de Paternidad Internacional MenCare?». Acceso: 06 de mayo, 2019. http://www.campanapaternidad.org/que-es-la-campana-de-paternidad mencare/?fbcli d=IwAR1mCoOjGluC23rsPznPENDwTFkWbrQ5E_NNEcxy-QCXaItenU3Vo514s9w

Campos, Álvaro; Salas, José Manuel. Masculinidades en Centroamérica. San José: Lara Segura Editores, 2002.

Chodorow, Nancy. La reproducción de la maternidad: Psicoanálisis y Sociología de Género. London: University of California Press, Ltd, 1979.

Connell, Raewyn. Masculinities. Cambridge: Polity Press, 1995.

Figueroa, Juan Guillermo. «Paternidad, mortalidad y salud: ¿es posible combinar estos términos» En Estudios sobre Varones y Masculinidades para la generación de políticas públicas y acciones transformadoras IV Coloquio Internacional de Estudios sobre Varones y Masculinidades. Montevideo. Acceso: 06 de mayo, 2019. https://www.academia.edu/6850483/Paternidad_mortalidad_y_salud_es_posible_combinar_ estos_t $\% \mathrm{C} 3 \% \mathrm{~A} 9 \mathrm{rminos}$

Foucault, Michel. Microfísica del Poder. Madrid: Las Ediciones de La Piqueta, 1979. Edición PDF.

Fuller, Norma. «No unos sino muchos rostros: Identidades masculinas en el Perú urbano». Acceso: 06 de mayo, 2019. http://bdigital.unal.edu.co/1403/6/05CAPI04.pdf

IPPF/WHR y Promundo. «Estado de la paternidad: América Latina y el Caribe 2017». Acceso: 06 de mayo, 2019. https://promundoglobal.org/wp-content/uploads/2017/06/2017-Informe-Estado-de-la-PaternidadLAC.pdf

Instituto sobre Alcoholismo y Farmacodependencia (IAFA). «VI encuesta nacional 2015: Consumo de drogas en Costa Rica». Acceso: 06 de mayo, 2019. https://www.iafa.go.cr/ investigaciones/540-vi-encuesta-nacional-2015-consumo-de-drogas-en-costa-rica. 
Jociles, María José. «El estudio sobre masculinidades: Panorámica general». Facultad de Ciencias Políticas y Sociología. Universidad Complutense de Madrid. Acceso: 06 de mayo, 2019. http://www.ugr.es/ pwlac/ G17_27MariaIsabel_Jociles_Rubio.html

Kaufman, Michael. «Los hombres, el feminismo y las experiencias contradictorias del poder entre los hombres». Acceso: 06 de mayo, 2019. http://www.michaelkaufman.com/wp-content/uploads/2008/12/los-hombres-el-feminismo-y-las-experiences-contradictorias-del-poder-entre-los-hombres.pdf

Kimmel, Michael. «Homofobia, temor, vergüenza y silencio en la identidad masculina». Acceso: 06 de mayo, 2019. http://hombressinviolencia.org/docs/HOMOFOBIA.pdf

Menjívar, Mauricio. «Hombres inventados. Estudios sobre masculinidad en Costa Rica y la necesidad de nuevos supuestos para el cambio social». Diálogos, Revista Electrónica de Historia, Vol. 8, n. ${ }^{\circ} 1$, (2007).

Menjívar, Mauricio. Masculinidad a debate. San José: Facultad Latinoamericana de Ciencias Sociales, 2010.

Olavarría, José. Los estudios sobre masculinidades en América Latina. Acceso: 06 de mayo, 2019. http://es.scribd. com/doc/20166517/Los-Estudios-Sobre-Masculinidad-en-America-Latina-Jose-Olavarria

Salas, José Manuel. Hombres que rompen mandatos: La prevención de la violencia. San José: Lara Segura \& Asociados, 2005.

Rivera, Roy y Ceciliano, Yajaira. Cultura, masculinidad y paternidad: Las representaciones de los hombres en Costa Rica. San José: FLACSO, 2004.

Torres, Laura Evelia. «La paternidad: Una mirada retrospectiva». Revista Ciencias Sociales, 105: 47-58 / 2004 (III).

Weber, Max. Ensayos sobre metodología sociológica. Buenos Aires: Amorrortu Editores, 1973. 